\title{
A Função do Treinamento na Emprêsa
}

\section{Francisco Gomes de Mattos}

Professor da Faculdade de Administração e Finanças da Universidade do Estado da Guanabara. Assessor de Desenvolvimento de Pessoal do Banco do Estado da

Guanabara

"A Função do Treinamento na Emprêsa" conquanto não seja a rigor um artigo, tem a sua presença na Revista do Serviço Público justificada pelo interêsse que o trabalho despertará entre os estudiosos de Administração Pública.

Sob a forma de aula ou conferência, apresentada ao ensejo do I Seminário de Gerentes, focaliza - Autor com objetividade um campo de estudo sempre atual para o Técnico de Administração. (NOTA DA REDACূAO).

$\mathrm{O}$

treinamento é um dos principais instrumentos de produtividade e esta decorre, principalmente, de dois fatôres: liderança e organização.

A liderança sem organização ou a organização sem liderança criam tôda sorte de desajustamentos, perdas de esforços, tempo, material e dinheiro. A falta dêsses elementos ou de um dêles, ou a má coordenação entre êles, são responsáveis pelo espirito de rotina, pela burocratização, pelas formalizações estéreis, pela re- 
sistência às inovações, pelas frustrações e pelos denominados "impossiveis".

Quando não se está

motivado a realizar;

quando não se sente

capacitado a realizar,

o "impossivel" é, simplesmente, uma saída cômoda.

A rigor, todavia, não há "impossivel", o que há é sentimento

e crença de impossibilidade.

O alvo principal do treinamento é o de acabar com os "impossiveis" na emprêsa. O "impossivel" não é nada diante de $99 \%$ de possibilidade. O êrro está em supervalorizar o $1 \%$ de dificuldades. O "impossivel" é, em geral, nada mais que um vício de imaginação. "Impossivel" significa falta de treinamento.

A função do treinamento é:

- Imprimir uma filosofia de atividade construtiva, à base de liderança (ação coordenada) e organização (atividade programada).

- Modificar hábitos viciados.

- Formar atitudes de trabalho.

O treinamento em si não constitui nenhuma solução miraculosa. Como instrumento, poderá ser usado com êxito ou não. Seu sucesso dependerá, além do apoio integral da Administração, de:

- seus objetivos,

- seus métodos. 
Quanto aos objetivos, é preciso considerar:

- pesquisa das necessidades de treinamento

- fixação das metas a serem atingidas,

- estabelecimento do fim principal. Quanto à seleção dos métodos, deverão ser empregados os
que melhor atendam:

- a satisfação das necessidades verificadas,

- a participação integral dos treinandos.

A rigor, só há treinamento quando a programação é baseada em análise das necessidades e atende ao que foi verificado como necelssário. Quando o curso não atende a êsse requisito essencial, será puramente de ilustração e aperfeiçoamento geral.

O treinamento, outrossim, deve apresentar respostas a problemas de trabalho. Quando o treinando não sabe como aplicar ções. O duvidoso, podem provocar descontentamentos e frustrapela sua funcionalidade.

O grande trabalho a ser realizado para que as programações de desenvolvimento do pessoal se tornem uma realidade na emprêsa é a criação do espirito de treinamento nas chefias.

E preciso que os Chefes - seja qual fôr seu grau hierárquico - estejam mentalizados no sentido de que o treinamento é sua principal responsabilidade. Pois o critério para aferição da boa ou má chefia é a análise da produtividade do seu grupo de
trabalho.

Se esta depende da coesão, dos padrões funcionais e do melhor desempenho de cada um da equipe, evidentemente o treinamento é, òbviamente, um encargo da chefia; a incumbência que poderá delegar a especialistas, quando se fizer necessário, mas, sôbre cuja responsabilidade deverá responder sempre.

O Chefe se mostra eficiente pela eficiência do seu grupo! Sua função básica é, pois, manter o grupo bem treinado. $\mathrm{E}$ tôdas
as funçoses de chefia são instrutoras, por excelência.

O Chefe:

- transmitindo ordens de serviço, 
- motivando o pessoal através de comunicações precisas,

— tomando decisões,

- delegando responsabilidades,

está treinando seut pessoal, desde que infunda à ação administrativa um propósito de aperfeiçoamento da equipe.

Sendo o treinamento um processo continuo, não se circunscreve a iniciativas sistematizadas por um setor especializado. Este, através de programação hábil, atenderá até certo ponto; depois, a responsabilidade maior é a dos que possuem responsabilidades administrativas. Os Chefes são, outrossim, os grandes responsáveis pelo aspecto mais importante: o acompanhamento.

Daí, para que o treinamento na emprêsa surta os resultados. esperados, de sustentação de iniciativas e realizaçốes, com vista a uma segura e autêntica expansão dos negócios, os Chefes precisam desenvolver-se dentro da filosofia de que são os intérpretes para sua equipe, da filosofia, das politicas e das diretrizes da emprêsa.

Portanto, o desenvolvimento do treinamento deve apoiar-se na colaboração decisiva das chefias,

- sugerindo,

- participando,

- instruindo e

- acompanhando

todo o trabalho de treinamento na emprêsa.

É preciso, outrossim, não se esquecer de que, acima de tudo, o treinamento é uma promoção humana e não promoção de capital. Não se adestra um homem como se lubrifica u'a máquina para produzir mais. Criam-se condições para que o homem seja mais eficiente no trabalho. $O$ treinamento é um dos meios mais dinâmicos de:

- habilitação profissional,

- divulgação das políticas da emprêsa,

- tomada de consciência e de decisões, 
- levantamento do moral.

- integração ao espírito da emprêsa.

Assim, o treinamento pode ser considerado sob duplo aspecto:

1 - Fator de Produtividade,

desenvolvimento:

- conhecimentos,

- técnicas.

formando:

— hábitos,

— atitudes.

2 - Recurso de Relações Humanas no Trabalho, visando:

- despertar o entusiasmo,

- estimular o espirito de cooperação,

- confraternizar membros do mesmo grupo ou de grupos diversos.

O treinamento infunde a convicção no pessoal de que o trabalho que realiza é importante e de que a Administração está interessada em seu aperfeiçoamento. Como conseqüência, obterse-á maior disposição para o trabalho, melhores comunicações, maiot eficiência, maior prestigio, maiores possibilidades de pro..
moção.

Assim, o treinamento, visando obter:

- eficiência no serviço,

- preparação para trabalho mais complexo,

- integração na estrutura social da emprêsa,

- formação de dirigentes,

é uma atividade continua na emprêsa e não pode ser considerado isoladamente. 
No primeiro caso, deve-se considerar que:

- quer por estar o homem permanentemente em processo de aperfeiçoamento;

- quer por ser a perspectiva de expansão uma constante em qualquer organização eficiente;

- quer pelo fato de estarem as técnicas em constante evolução, exigindo periódica atualização de conhecimentos, para não se deixar superar;

- quer porque hoje, unânimemente, as autoridades em administração consideram o pessoal como principal recurso empresarial,

o treinamento afigura-se como atividade sistemática, tanto através de iniciativas de ordem formal. quanto informal.

No segundo caso, é preciso que se fixe que o treinamento, para surtir o efeito esperado, depende de outras providências administrativas. Não se pode treinar um homem e... pronto: esperar que êle renda como um autômato. É preciso compensar seu esfôrço de aperfeiçoamento. Dar-lhe condições de expansão, maior prestigio, maiores responsabilidades, possibilidades de promoção (horizontal e vertical). Portanto, o treinamento deve apoiar-se em uma adequada Politica de Pessoal. dentais:

Pois, em qualquer emprêsa, existem três questões transcen-

- Como fixar os bons empregados.

- Como recrutar os que faltam.

- Como aumentar a eficiência do pessoal.

Temos, assim:

- um problema de Politica Social na Emprêsa,

- um problema de Recrutamento e Seleção e

- um problema de Treinamento. 
A formulação de uma teoria empresarial, manifesta em diretrizes e normas de ação, nestas três áreas, consubstancia a filosofia da emprêsa em relação ao seu pessoal.

AS RESPONSABILIDADES PELO TREINAMENTO NA EMPRÊSA

A responsabilidade pelo treinamento, na emprêsa, distribui-se por 3 categorias:
a) Administração Superior
b) Órgão Especializado
c) Os Chefes

\section{I - À Administração \\ Superior}

compete

\section{II - Ao Órgão \\ Especializado}

a) Traçar a Politica de Treinamento.

b) Criar condições para que se realizem as diretrizes de treinamento.

c) Coordenar a atuação dos Responsáveis pelo treinamento.

a) Pesquisar as necessidades de treinamento.

b) Estabelecer programas em função da filosofia, politicas e práticas da Emprêsa.

c) Promover iniciativas que, direta ou indiretamente, resultem em promoção humana e produtividade.

d) Assessorar a Administração nos assuntos relacionados com o desenvolvimento do pessoal. 
Observações: A necessidade de um órgão especializado de treinamento na emprêsa justifica-se pelas seguintes razões:

a) A maneira das necessidades de treinamento é comum aos vários setores da emprêsa, indicando a conveniência de centralização de atividades fora do local de trabalho.

b) O órgão especializado, por fôrça de suas atividades, está mais alertado para as soluçṍes de treinamento do que os Chefes, absortos pela rotina de trabalho.

c) Os Chefes nem sempre possuem condições de se manterem atualizados com as técnicas modernas de administração e o desenvolvimento dos métodos de ensino.

III - Aos Chefes

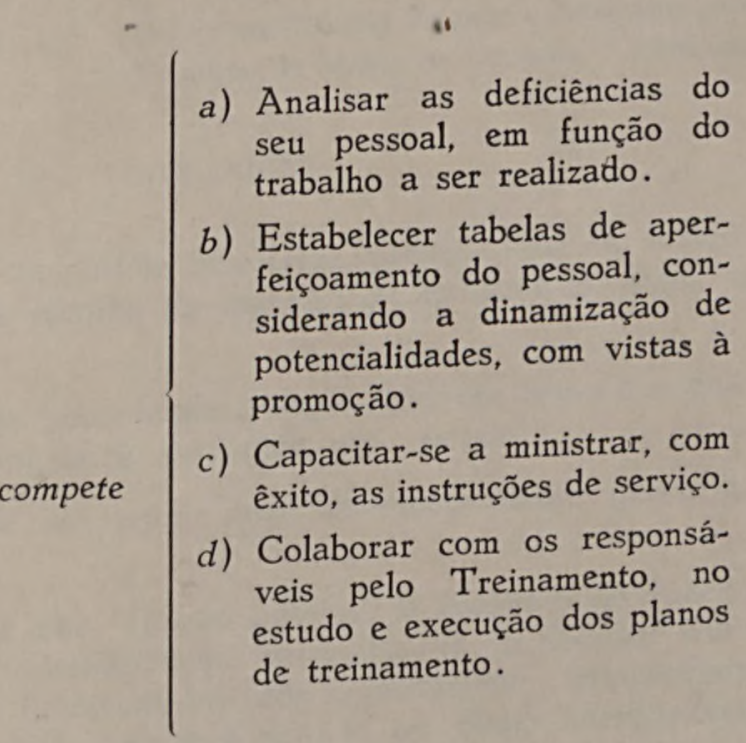

Observações:

a) O Chefe é quem melhor pode avaliar:

a.1) O trabalho a ser realizado.

a.2). As qualificações necessárias ao seu pessoal para realizá-lo bem.

b) O Chefe é quem melhor pode sentir a necessidade de pessoal competente para:

b.1) Cumprir suas ordens de serviço.

b.2) Atender às cotas de produção estipuladas. 


\section{Portanto:}

- A Administração Superior deve definir as metas a serem atingidas.

- A responsabilidade pelas programações de treinamento deve ser centralizada, embora, nem sempre, sua execução.

- Os Chefes devem ter participação ativa no planejamento e na execução do treinamento. 